\title{
ANALYSIS OF HAZARDS ASSOCIATED WITH A PROCESS INVOLVING URANIUM METAL AND URANIUM HYDRIDE POWDERS
}

\author{
J. S. Bullock \\ Chemistry and Chemical Engineering Department \\ Development Division
}

Issue Date: May 2000

\author{
Prepared by the \\ Oak Ridge Y-12 Plant \\ Oak Ridge, Tennessee 37831 \\ operated by \\ Lockheed Martin Energy Systems, Inc. \\ for the \\ U. S. Department of Energy \\ under contract DE-AC05-84OR21400
}




\section{DISCLAIMER}

This report was prepared as an account of work sponsored by an agency of the United States Government. Neither the United States Government nor any agency thereof, nor any of their employees, makes any warranty, express or implied, or assumes any legal liability or responsibility for the accuracy, completeness, or usefulness of any information, apparatus, product, or process disclosed, or represents that its use would not infringe privately owned rights. Reference herein to any specific commercial product, process, or service by trade name, trademark, manufacturer, or otherwise, does not necessarily constitute or imply its endorsement, recommendation, or favoring by the United States Government or any agency thereof. The views and opinions of authors expressed herein do not necessarily state or reflect those of the United States Government or any agency thereof. 


\title{
Analysis of Hazards Associated with a Process Involving Uranium Metal and Uranium Hydride Powders
}

\author{
J. S. Bullock \\ Chemistry and Chemical Engineering Department \\ Development Division
}

Issue Date: May 2000

\author{
Prepared by the \\ Oak Ridge Y-12 Plant \\ Oak Ridge, Tennessee 37831 \\ operated by \\ Lockheed Martin Energy Systems, Inc. \\ for the \\ U. S. Department of Energy \\ under contract DE-AC05-84OR21400
}




\section{TABLE OF CONTENTS}

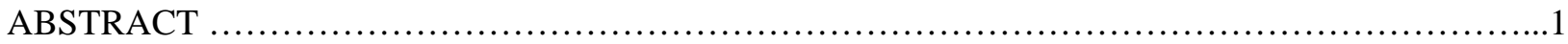

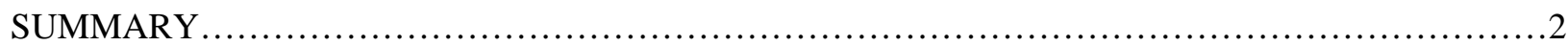

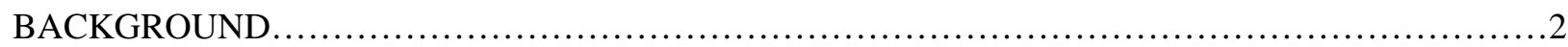

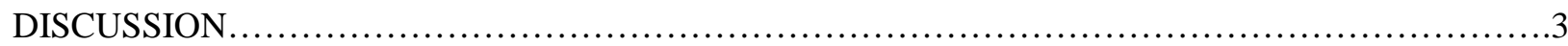

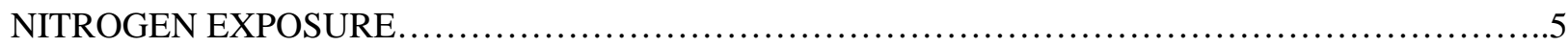

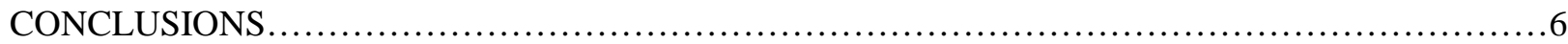

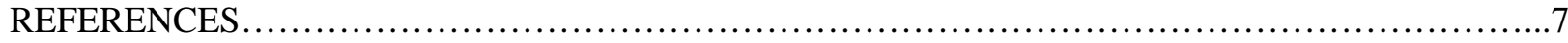




\begin{abstract}
An analysis of the reaction chemistry and operational factors associated with processing uranium and uranium hydride powders is presented, focusing on a specific operation in the Development Division which was subjected to the Job Hazard Analysis (JHA) process. Primary emphasis is on the thermodynamic factors leading to pyrophoricity in common atmospheres. The discussion covers feed powders, cold-pressed and hot-pressed materials, and stray material resulting from the operations. The sensitivity of the various forms of material to pyrophoricity in common atmospheres is discussed. Operational recommendations for performing the work described are given.
\end{abstract}




\section{SUMMARY}

An analysis of the reaction chemistry and operational factors associated with processing uranium and uranium hydride powders is presented, focusing on a specific operation in the Development Division which was subjected to the Job Hazard Analysis (JHA) process. Primary emphasis is on the thermodynamic factors leading to pyrophoricity in common atmospheres. Operational recommendations for performing the work described are given.

\section{BACKGROUND}

A JHA concerning the processing of uranium metal and uranium hydride powders was submitted to the Y12 Development Division HazMat Analysis Process. To supplement the information provided on the JHA form, discussions with Development personnel provided a more complete description of the intended process, which is summarized here. For the immediate application, the internal Development customer will provide lots of powder to the Development personnel processing the material into solid compacts, which will be returned to the internal customer for further processing. However, this JHA applies to a wider range of operations than the immediate application.

If the supplied powder material is not already totally uniform, it will be blended inside an inert-atmosphere glovebox using a V-blender. The blended material will be removed from the blender and poured either into an intermediate storage container or directly into a pressing die.

From here there are two parallel processes that can be used. One is a cold-pressing process inside the same glovebox; the other is a hot-pressing process using a system remote from this glovebox. The cold-pressing operation uses uncoated metal (steel) dies and plugs with a working chamber diameter of 1.0 to 1.5 inches. The seal is reasonably good between the plugs and die bodies so that a minimal amount of powder will bypass the seal, although leakage of small amounts is possible and that material will not be consolidated. With a plug in the bottom, a charge of powder will be loaded and a plug inserted in the top. The assembly with die, bottom plug, charge, and top plug will be placed into the manually-operated hydraulic press and up to 12 tons of force applied. For a 1-in ID die, this will yield 30.6 Ksi pressure; for a 1.5-in ID die, 13.6 Ksi. Following release of pressure, the configuration will be changed to permit the ram to press out the compacted material. This compacted object will then be loaded into a sealed container for transfer out of the glovebox to the customer.

The dies, plugs and internal shims for the hot-pressing operation are fabricated from Poco graphite and coated with yttria paint. The dies are right cylinders approximately 18 inches long and 14 inches OD. There is a concentric hole along the cylindrical axis of diameter 3 to 4 inches. Prior to loading the powders, a coated plug of length on the order of its diameter is inserted into the bottom opening of the die, and a bead of colloidal graphite suspension is applied to the outside of the assembly in order to seal the seam between the plug and the ID of the die. The die is righted and filling of the charge can commence. Large charges can be broken up using coated shim disks inserted between segments of the charge. When the final charge increment is added, a coated top plug is inserted and the seam between it and the ID of the coated die also sealed with a bead of colloidal graphite suspension. At this point the die can be transferred out of the glovebox to the hot press and positioned with respect to the ram. The press enclosure is closed and evacuated in preparation for either vacuum or argon operation. The graphite die is heated by an induction coil to a maximum of $1200 \mathrm{C}$. The total ram force applied is a maximum of 20 tons. For a 3-inch ID die, this will yield $5.66 \mathrm{Ksi}$; for a 4-inch die, $3.18 \mathrm{Ksi}$.

In operation, as the hot-press die temperature rises to several hundred degrees $\mathrm{C}$, the colloidal graphite seal 
loses integrity and the die chamber becomes an open system. This is important in the case of processing hydride powders. Uranium hydride decomposes to uranium metal and hydrogen gas as the temperature rises, reaching one atmosphere at $435 \mathrm{C}$. At $1200 \mathrm{C}$ an overpressure of $9.8 \mathrm{Ksi}$ hydrogen ${ }^{1}$ could be created over a mass of uranium hydride. Thus, it is important that the temperature of the die rise slowly enough, especially above $435 \mathrm{C}$, to allow the decomposition with release of hydrogen gas to proceed with leakage of gas around the die-plug seals as a pressure-relief mechanism. This operation will be done under continuous pumping. I am informed that this same operation has been done many times before, and as recently as 1998, with success.

On completion of hot-pressing, the die will be transferred from the hot press to an open but vented enclosure, where the consolidated material will be pressed out of the die with a hydraulic press.

\section{DISCUSSION}

I will assume that standard industrial safety hazards such as hoisting \& lifting are separately covered.

The primary material hazard associated with this operation seems to be potential pyrophoricity. It is known that finely divided $\mathrm{U}$ and $\mathrm{UH}_{3}$ will react vigorously with air when a stimulus such as friction and/or sparking is present. It is instructive to look at the enthalpies released by these reactions. To stay with a common stoichiometry for most of the calculations, consider that for finely divided $\mathrm{UH}_{3}$ exposed to $\mathrm{O}_{2}, \mathrm{H}_{2}$ gas is liberated and the uranium oxide formed is $\mathrm{UO}_{\mathrm{x}}$, where $\mathrm{x}=2.15 \forall 0.05$. For our purposes we will use the value $\mathrm{x}=2.1667$, which permits balancing equations with smaller integral numbers and is within the error band. It should be noted that $\mathrm{UH}_{3}$ powder does not appear to effectively passivate when exposed to oxygen $^{2}$, although $\mathrm{U}$ powder does to some extent.

$\begin{array}{llll}\text { Rx 1: } & 12 \mathrm{U}+13 \mathrm{O}_{2}= & 12 \mathrm{UO}_{2.1667} \\ \text { Rx 2: } & 12 \mathrm{UH}_{3}+13 \mathrm{O}_{2}= & 12 \mathrm{UO}_{2.1667}+18 \mathrm{H}_{2} \\ \text { Rx 3: } & 12 \mathrm{UH}_{3}+22 \mathrm{O}_{2}= & 12 \mathrm{UO}_{2.1667}+18 \mathrm{H}_{2} \mathrm{O} \\ \operatorname{Rx} \text { 4: } & 12 \mathrm{UH}_{3}+25 \mathrm{O}_{2}= & 4 \mathrm{U}_{3} \mathrm{O}_{8}+18 \mathrm{H}_{2} \mathrm{O}\end{array}$

Reactions 1 and 2 represent the initial stages of oxidation reactions that may occur on exposure of the $\mathrm{U}$ and $\mathrm{UH}_{3}$ powders respectively. If an ignition source raises the temperature locally, the $\mathrm{H}_{2}$ liberated in reaction 2 can ignite and form water vapor as in reaction 3, with a correspondingly higher enthalpy release. Further increases in temperature make it more likely that the higher oxide $\mathrm{U}_{3} \mathrm{O}_{8}$ will form, with somewhat higher enthalpy releases.

As will be seen in the Tables to follow, the specific enthalpy releases per unit reactant are very high, and combined with the specific heat $\left(\mathrm{C}_{\mathrm{p}}\right)$ values predict extremely high temperature excursions for these materials once they ignite. Enthalpy of formation values except where noted were taken from a standard reference ${ }^{3}$. This includes data for $\wedge \mathrm{H}_{\mathrm{f}}$ of water which is not listed but was used in reaction enthalpy calculations. The $\boldsymbol{}_{\mathrm{H}} \mathrm{H}_{\mathrm{f}}$ for $\mathrm{UH}_{3}(-30.35 \mathrm{Kcal} / \mathrm{mole})$ was taken from a separate reference ${ }^{4}$. All enthalpy and free energy values in this document are for $298 \mathrm{~K}$. 
Table 1 - $\rightarrow \mathrm{H}_{\mathrm{f}}$ of Specific Uranium Oxides

\begin{tabular}{|c|l|}
\hline Oxide & \multicolumn{1}{|}{$\mathbf{A \mathbf { H } _ { \mathbf { f } } \text { (cal/mole) }}$} \\
\hline $\mathrm{UO}_{2}$ & -259300 \\
\hline $\mathrm{UO}_{2.1667}$ & -266685 (est.) \\
\hline $\mathrm{UO}_{2.3333}$ & -273030 \\
\hline $\mathrm{UO}_{2.6667}$ & -284800 \\
\hline $\mathrm{UO}_{3}$ & -292500 \\
\hline
\end{tabular}

The values for all but the $\mathrm{UO}_{2.1667}$ were taken from the $\mathrm{CRC}$ handbook. The exception was estimated by curve-fit of the CRC data ${ }^{5}$ and evaluation at that stoichiometry.

The effect of a given enthalpy release depends on the specific heat of the materials. For the present let us just consider the reactant specific heats to get a feel for the relative acceleration of the oxidation reactions. These are shown in Table 2 for both $300 \mathrm{~K}$ and as an estimated average value from $300 \mathrm{~K}$ to $858 \mathrm{~K}$, which is the autoignition temperature ${ }^{6}$ for hydrogen.

Table 2 - $\mathrm{C}_{\mathrm{p}}$ of Reactants

\begin{tabular}{|c|c|c|}
\hline Reactant & $\mathbf{C}_{\mathbf{p}}$ @ $\mathbf{3 0 0 K}\left(\mathrm{cal} / \mathrm{mole}^{* K}\right)$ & ave. $\mathbf{C}_{\mathbf{p}}$ over 300K to 858K \\
\hline $\mathrm{U}$ & 6.65 & 8.09 \\
\hline $\mathrm{UH}_{3}$ & 11.84 & 22.2 \\
\hline
\end{tabular}

These values yield for the several reactions values of enthalpy release per mole reactant and per gram reactant. I have also used the $C_{p}$ values ${ }^{7}$ to estimate an initial Temperature Rise Index (TRI) and the ratios of these TRIs to see what the initial relative heating effect might be.

Table 3 - Heating Effects for Reactions

\begin{tabular}{|c|c|c|c|c|}
\hline Reaction & $\boldsymbol{\uparrow} \mathbf{H r x}(\mathrm{cal} / \mathrm{mole})$ & $\boldsymbol{\uparrow} \mathbf{H r x}(\mathrm{cal} / \mathrm{g})$ & $\mathbf{T R I}(\mathrm{K})$ & TRI Ratio \\
\hline 1 & -266685 & -1120.5 & 32965 & 3.10 \\
\hline 2 & -236335 & -980.64 & 10646 & 1.00 \\
\hline 3 & -323029 & -1340.4 & 14551 & 1.37 \\
\hline 4 & -341144 & -1415.5 & 15367 & 1.44 \\
\hline
\end{tabular}

Thus, the lower $C_{p}$ of metallic $U$ causes this measure of heating effect to be more extreme than for the hydride. However, it is quite likely that the hydride has faster kinetics of oxidation than the metal (probably connected with its inability to passivate), which would boost the temperature increase rate to values possibly higher than those for metal oxidation. In addition, the gas production in the hydride powder oxidations may cause significant movements of particulate material, whereas with a metal powder this is much less significant and by and large it should just sit and smoulder, partially sintering as it goes 
which will tend to reduce the oxidation rate.

In contrast, the experience of spark- or friction-initiated hydride fires is that they can be quite impressive. The INEEL personnel that are funding the local $\mathrm{UH}_{3}$ Pyrophoricity Project ${ }^{8}$ have seen quite a bit of sensitivity to friction and sparking for hydride powder exposed to air. Friction in this case can result from as simple a cause as pouring from one container to another.

\section{NITROGEN EXPOSURE}

Although not specifically considered in the subject JHA, it seemed prudent to discuss briefly the possibility of exposure of such powders to nitrogen gas, as the possibility of using $\mathrm{N}_{2}$ as a cover gas for reactive materials periodically comes up. I have previously examined the literature on the relative gas consumption rates, between the temperatures of $550 \mathrm{C}$ and $1000 \mathrm{C}$, of uranium exposed to dry air ${ }^{9}$ and to pure nitrogen ${ }^{10}$. The ratio of the two rates is about $32.6 \forall 10 \%$ with nitrogen being the slower. Thus, while uranium metal powder may actually have the potential for pyrophoricity in $\mathrm{N}_{2}$, it would probably require a surface-tovolume ratio greater than that for pyrophoricity in $\mathrm{O}_{2}$ by a large factor, perhaps $33 \mathrm{X}$.

For $\mathrm{UH}_{3}$ powder, there are 3 factors that argue for the plausibility of pyrophoricity in $\mathrm{N}_{2}$ : (1) hydride powders typically have higher surface-to-volume ratios than metal powders; (2) the specific reaction rate of the hydride may be higher than the metal; and (3) pyrophoricity has, in fact, been observed ${ }^{11}$. Two possible reactions for $\mathrm{UH}_{3}$ in $\mathrm{N}_{2}$ gas are as follows:

Rx 1: $\quad 2 \mathrm{UH}_{3}+2 \mathrm{~N}_{2}=\quad 2 \mathrm{UN}+3 \mathrm{H}_{2}$

Rx 2: $\quad \mathrm{UH}_{3}+\mathrm{N}_{2}=\mathrm{UN}+\mathrm{NH}_{3}$

Some pertinent thermodynamic information is given in Tables $4 \& 5$.

Table 4 - Thermodynamic Parameter Values Pertinent to Nitrogen Exposure

\begin{tabular}{|c|c|c|}
\hline Compound & $\boldsymbol{A ~}_{\mathbf{f}}(\mathbf{c a l} / \mathbf{m o l e})$ & $\boldsymbol{A G}_{\mathbf{f}}(\mathbf{c a l} / \mathbf{m o l e})$ \\
\hline $\mathrm{UH}_{3}$ & -30350 & -17590 \\
\hline $\mathrm{UN}$ & -69500 & -63500 \\
\hline $\mathrm{NH} 3$ & -11020 & -3940 \\
\hline
\end{tabular}

The use of these values yields free energy changes and enthalpy releases per mole of $\mathrm{UH}_{3}$ which are somewhat larger for Rx 2 than for Rx 1, as is shown in Table 5.

Table 5 - $\wedge G_{\mathrm{rx}}$ and $\wedge \mathrm{H}_{\mathrm{rx}}$ for Reactions $1 \& 2$

\begin{tabular}{|c|c|c|}
\hline Reaction & $\boldsymbol{\wedge} \mathbf{G}_{\mathbf{r x}}\left(\mathbf{c a l} / \mathbf{m o l e} \mathbf{U H}_{\mathbf{3}}\right)$ & $\boldsymbol{\uparrow} \mathbf{H}_{\mathrm{rx}}\left(\mathbf{c a l} / \mathbf{m o l e} \mathbf{U H}_{\mathbf{3}}\right)$ \\
\hline 1 & -45910 & -39150 \\
\hline 2 & -49850 & -50170 \\
\hline
\end{tabular}


Thus, the second reaction leading in part to $\mathrm{NH}_{3}$ formation is slightly more favorable from a free energy standpoint, but has a significantly higher enthalpy release and so may cause greater auto-acceleration of the reaction. To fully evaluate this would require incorporation of $\mathrm{C}_{\mathrm{p}}$ factors for all the reactants and products, which I will not do in this document.

However, the fact remains that pyrophoricity of $\mathrm{UH}_{3}$ powder in $\mathrm{N}_{2}$ gas has been observed. Thus, under no circumstances should $\mathrm{UH}_{3}$ powder be exposed to either $\mathrm{N}_{2}$ or any of its mixtures with oxygen, including air.

\section{CONCLUSIONS}

No significant quantities of either uranium or uranium hydride powder should be allowed significant access to air. The integrity of transfer containers should be absolute and they should be unbreakable. Operations inside the glovebox should be no problem as long as the integrity of the inert atmosphere is maintained. Should the box be breached, all containers should be closed. Should atmosphere integrity be lost during the blending cycle, the blender should be stopped and no attempt to move or transfer the powder should be made until atmospheric integrity is restored and the blender has time to reequilibrate with the inert gas.

The cold-pressing operation will lead to a somewhat porous compacted body which nevertheless has some strength. This may be the most sensitive form of the material, since friction against certain materials (or fracture of the compacted body) can cause generation of heat and sparks at the surface. This material would still have a small particle size for a large surface-to-volume ratio, some porosity to allow air access into the surface, and probably a lower heat conductivity due to lessened interconnectivity between particles compared to fully consolidated material. Thus, any heat generated in a local reaction may not be drained off into the matrix fast enough and a self-propagating reaction may occur. There may be a good chance that the cold-pressed compact exposed to air would ignite if struck by a metal object. For the metal powder, only smoldering may occur; for the hydride, consequences could be more severe and significant dispersal of particulates may occur. Debris resulting from the pressing operation, such as powder that may bypass the press ram or that may be spilled during loading, will not be consolidated but will still be sensitive to friction.

For hot-pressed material, consolidation should be adequate to reduce porosity to near zero and raise heat conductivity near theoretical. Thus, the subsurface region will have no access to air and the heat from any surface reaction should be quenched into the matrix. While this material may spark when struck by metal, there would be no further reaction. Small particulate debris not consolidated into the body of the material, but that has been through the temperature cycle, would probably have reduced reactivity but may still ignite when sparked. Even fully consolidated U material oxidizes freely at several hundred degrees C; above $300 \mathrm{C}$ the rate accelerates with time ${ }^{12}$. Thus, the temperature of the die should be allowed to cool comfortably below $300 \mathrm{C}$ before removal from the press, and before the press-removal from the die in open air the temperature should probably be allowed to drop below 100C. Limited ignitions of debris that do not lead to particulate dispersal should not be a problem. There should be some means of verifying that dispersal did not occur.

It is advisable there should also be some means of positively verifying the free outgassing of hydrogen gas during the hot-pressing of hydride powder for making solid metal compacts.. 


\section{REFERENCES}

1. Metal Hydrides; W.M.Mueller, J.P. Blackledge \& G.G. Libowitz; temperature-corrected from data on p.500; Academic Press (1968)

2. G. L. Powell, unpublished data (1999-2000)

3. CRC Handbook of Chemistry and Physics, $70^{\text {th }}$ Edition

4. Metal Hydrides; p.512

5. TableCurve software; Jandel Scientific (1992)

6. Is Hydrogen Safe?; Report NBS-TN-690, p.6; US Dept. of Commerce (Oct. 1976)

7. CRC Handbook // Metal Hydrides, p.527 (extrapolated)

8. Chemical Reactivity Testing for the National Spent Nuclear Fuel Program - Quality Assurance Project Plan; Report Y/DZ-2151, Rev.2; LMES (Feb. 8, 2000)

9. A.G. Ritchie, J. Nucl. Mater., Vol. 120 (1984), p. 143

10. M.W. Mallett \& A.F. Gerds, J. Electrochem. Soc., Vol. 102 (1955), No. 6, pp.292 - 296

11. G.L. Powell, personal communication

12. AGaseous Oxidation of Uranium Alloys@, J.V. Cathcart; in Physical Metallurgy of Uranium Alloys, p.789; Brook Hill Publishing Co. (1976) 


\section{DISTRIBUTION}

Idaho National Engineering and Environmental Laboratory

C. A. Dahl

Y-12 Plant

J. S. Bullock (4)

E. L. Bird

M. C. Christofferson

A. L. DeMint

J. G. Gooch

L.W. Koester

M. J. O’Hara /M.L. Baker

G. L. Powell

Y-12 Central Files--RC 